\title{
A DIVULGAÇÃO DA GINÁSTICA GERAL: IDENTIFICAÇÃO DE UMA PROBLEMÁTICA A PARTIR DE UM ESTUDO DE CASO
}

Beatriz Castelló Cruz, Universidade Estadual de Campinas - UNICAMP, Campinas, São Paulo - Brasil

Elizabeth Paoliello Machado de Souza, Universidade Estadual de Campinas - UNICAMP, Campinas, São Paulo - Brasil

Eliana de Toledo, Universidade Estadual de Campinas - UNICAMP, Campinas, São

Paulo - Brasil

\section{RESUMO}

Muitos são os indicadores que apontam para um crescente desenvolvimento da ginástica geral (ou ginástica para todos) no Brasil. Por outro lado, também parece notório que sua divulgação ainda caminha a passos lentos, dentro e fora da área da Educação Física. Neste contexto, este artigo tem como objetivo apresentar os dados obtidos numa pesquisa, para a partir dela apresentar reflexões, apontamentos de algumas problemáticas e soluções acerca da divulgação desta manifestação da cultura corporal em âmbito nacional. A pesquisa caracterizou-se como um estudo de caso, inicialmente com fontes documentais (veículos de comunicação da UNICAMP) e posteriormente foi realizada uma pesquisa de campo com os alunos da UNICAMP, de caráter exploratório, cujo instrumento foi um questionário, respondido por 145 alunos quarto anistas, de diferentes cursos de graduação. Os dados evidenciaram que há um alto índice de alunos que não sabe o que é a ginástica geral, e tão pouco sabem os trabalhos desenvolvidos pelo Grupo Ginástico Unicamp (GGU), em atividade há 23 anos, e pelo Grupo de Pesquisa em Ginástica da FEF Unicamp, fundado em 1993. Estes dados, somados a uma pesquisa bibliográfica, possibilitaram um olhar mais ampliado para a divulgação da ginástica geral no país, analisando-se as fragilidades e as possibilidades de superação deste quadro.

Palavras-Chave: Ginástica geral; Ginástica para todos; Divulgação; Veículos de comunicação; UNICAMP.

\section{THE DISSEMINATION OF GENERAL GYMNASTICS: IDENTIFICATION OF A PROBLEM FROM A CASE STUDY}

\begin{abstract}
There are many indicators that point to an increasing development of General Gymnastics (Gymnastics for all) in Brazil. On the other hand, it seems clear that the dissemination of the concept inside and outside the area of Physical Education still walks with slow steps. In this context, this article aims to present the data obtained in a case study survey, highlighting some problems and solutions regarding the dissemination of this body culture manifestation in Brazil. The research was characterized as a documentary, using data available in different internal communication vehicles at Unicamp (study case), as well as specific vehicles for the dissemination of gymnastics. A field survey was conducted targeting senior students of different courses offered by UNICAMP. The sample consisted of 100 senior students from 45 institutes and colleges, totaling 145 respondents. The data


showed that there is a high rate of students who do not know what general gymnastics is and little aware of the work undertaken by Gymnastic Group Unicamp (GGU), established 23 years ago, and the Research Group in Gymnastics Unicamp. Based on these data and the analysis of other aspects, it is possible to envision new paths for the dissemination of General Gymnastics in Brazil.

Key-Words: General gymnastics; Gymnastics for all; Dissemination; Communication vehicles; UNICAMP.

\section{LA DIVULGACIÓN DE LA GIMNASIA GENERAL: IDENTIFICACIÓN DE UNA PROBLEMÁTICA A PARTIR DE UN ESTUDIO DE CASO}

\section{RESUMÉN}

Muchos son los indicadores que apuntan a un incremento en el desarrollo de la gimnasia general (o gimnasia para todos) en Brasil. Por otro lado, también es destacable que su divulgación todavía camina a pasos lentos, dentro y fuera de la Educación Física. En este contexto, este artículo tiene como objetivo presentar los datos obtenidos en una investigación de un estudio de caso, sobre la divulgación de la gimnasia general en la Unicamp, y traer de manera inédita, reflexiones, apuntes sobre algunos de los problemas y soluciones acerca de la divulgación de esta manifestación de la cultura corpora en todo Brasil. El estudio se caracterizó como documental, apoyándose en datos disponibles en diferentes medios de comunicación internos de la Unicamp (estudio de caso), así como medios específicos de difusión de la gimnasia. Se realizó un estudio de campo, de carácter exploratorio, a través de un cuestionario, con preguntas abiertas y cerradas, direccionadas a 145 alumnos cuarto anistas de los diferentes cursos ofertados por la Unicamp. Los datos muestran que hay un alto índice de alumnos que no conoce lo que es la gimnasia general, y tampoco los trabajos desarrollados por el Grupo Gimnástico Unicamp (GGU), creado hace 23 años, ni por el Grupo de Investigación en Gimnasia de la FEF Unicamp, fundado en 1993. A partir de estos datos y del análisis de otros aspectos, se hace evidente también una estructura todavía precaria de divulgación de la GG en el país.

Palabras-Clave: Gimnasia general; Gimnasia para todos; Divulgación; Medios de comunicación; UNICAMP. 


\section{INTRODUÇÃO}

O trabalho apresentado parte de uma pesquisa desenvolvida e aprovada pelo Programa Institucional de Bolsas de Iniciação Científica (PIBIC/CNPq), financiada pelo Serviço de Apoio ao Estudante (SAE/UNICAMP) e desenvolvida no período de Agosto de 2006 a Julho de 2007, tendo como título: O Conhecimento sobre a Ginástica Geral na Unicamp. Este projeto de pesquisa já foi publicado de diferentes maneiras em dois eventos específicos da área da Ginástica, Cruz e Paoliello, ${ }^{1-2}$ no entanto, seus resultados ainda não o foram.

A pesquisa motivou-se inicialmente pela percepção de que apesar de haver na Faculdade de Educação Física da UNICAMP, desde 1989, um Grupo de Pesquisa em Ginástica e de um grupo de apresentação em Ginástica Geral (Grupo Ginástico Unicamp - GGU), reconhecido nacional e internacionalmente, os estudantes dessa universidade pareciam desconhecer essa manifestação da cultura corporal.

E se caracterizou como de estudo de caso, de caráter exploratório e documental. As fontes documentais foram advindas de diferentes meios de comunicação da Unicamp (posteriormente apresentadas), e a pesquisa exploratória utilizou-se da aplicação de questionários, ambos tendo como objetivo diagnosticar o conhecimento sobre a Ginástica Geral (GG) na UNICAMP, principalmente entre os alunos de graduação.

Os resultados da pesquisa, publicados de forma inédita em artigo neste texto, deflagram algumas problemáticas de divulgação da GG, pelo referido Grupo de Pesquisa e pela UNICAMP, assim como abordou reflexões e propostas para saná-las. 
Os dados obtidos nesta pesquisa permitiram o desenvolvimento de uma segunda pesquisa, aqui apresentada, viabilizando a análise outras questões referentes à divulgação da GG em âmbito nacional e o apontamento de algumas sugestões para que ela ocorra de forma ampliada, e talvez mais significativa.

\section{A Ginástica Geral}

A ginástica geral pode ser compreendida e definida de formas distintas. Segundo a Federação Internacional de Ginástica (FIG):

A Ginástica Geral é a área da Ginástica orientada para o lazer, [...] é composta por uma variedade de atividades esportivas disponíveis para todos os grupos de idade, compreendendo essencialmente exercícios no campo da Ginástica, com e sem aparelhos, assim como jogos de caráter nacional e cultural. A Ginástica Geral desenvolve a saúde, a manutenção da forma física e a integração social. ${ }^{3: 24}$

Para a FIG, ela é uma atividade não seletiva que agrega participantes independente do nível de desempenho, idade e sexo, atraindo, por isso, um grande número de pessoas. Esta prática estimula a criatividade, o bem-estar e a união entre as pessoas, além de incluir tradições, simbolismos e valores culturais de cada povo. E

dentre a enorme diversidade de possibilidades de sua prática, a Ginástica Geral compreende as seguintes atividades, desde que sem caráter competitivo: Ginástica (exercícios com e sem aparelho), Dança e Jogos. $^{4: 34}$

Outros conceitos e concepções foram desenvolvidos por outros autores e instituições (uma parte delas reunida na obra de Toledo e Schiavon), ${ }^{5}$ mas através dos aqui apresentados nota-se que a ginástica geral compreende todas as manifestações pertencentes a estes universos da ginástica, dança e jogos; e em sua grande maioria não competitivas. E justamente devido a esta diversidade e amplitude de manifestações que contempla, é que torna-se difícil estabelecer sua definição. 
Outras concepções e conceitos são a ela atribuídos, segundo podemos analisar de forma sucinta no quadro a seguir:

Quadro 1 - Comparação das Definições de Ginástica Geral

\begin{tabular}{|c|c|c|c|c|}
\hline $\begin{array}{l}\text { GINÁSTICA } \\
\text { GERAL }\end{array}$ & FIG & SANTOS; SANTOS & AYOUB $^{7}$ & GGU \\
\hline ORIENTAÇÃ̃O & Lazer & Lazer & $\begin{array}{l}\text { Composição entre os } \\
\text { elementos da } \\
\text { Ginástica Científica } \\
\text { e do núcleo } \\
\text { primordial da } \\
\text { Ginástica }\end{array}$ & $\begin{array}{l}\text { Capacitação e } \\
\text { formação humana }\end{array}$ \\
\hline ATIVIDADES & $\begin{array}{l}\text { Ginástica } \\
\text { (exercícios com e } \\
\text { sem aparelho), } \\
\text { Dança e Jogos }\end{array}$ & $\begin{array}{l}\text { Ginástica, valendo-se de } \\
\text { vários tipos de } \\
\text { manifestações, tais } \\
\text { como, danças, } \\
\text { expressões folclóricas e } \\
\text { jogos }\end{array}$ & $\begin{array}{l}\text { Ginástica, ginástica } \\
\text { científica e diversas } \\
\text { manifestações } \\
\text { gímnicas } \\
\text { contemporâneas, } \\
\text { dialogando com } \\
\text { outros elementos do } \\
\text { universo da cultura } \\
\text { corporal }\end{array}$ & $\begin{array}{l}\text { Ginástica (Natural, } \\
\text { Construída, } \\
\text { Artística, Rítmica } \\
\text { Desportiva, } \\
\text { Aeróbica, etc.) } \\
\text { integrando-as com } \\
\text { outras formas de } \\
\text { expressão corporal }\end{array}$ \\
\hline PRATICANTES & $\begin{array}{l}\text { Todos os grupos } \\
\text { de idades }\end{array}$ & $\begin{array}{l}\text { Qualquer nível técnico, } \\
\text { sexo ou idade }\end{array}$ & $\begin{array}{l}\text { Aberta para a } \\
\text { participação de } \\
\text { todos }\end{array}$ & $\begin{array}{l}\text { Qualquer grupo } \\
\text { social }\end{array}$ \\
\hline BENEFÍCIOS & $\begin{array}{l}\text { Desenvolve a } \\
\text { saúde, a } \\
\text { manutenção da } \\
\text { forma física e a } \\
\text { integração social }\end{array}$ & $\begin{array}{l}\text { Bem estar físico, } \\
\text { psíquico e social }\end{array}$ & $\begin{array}{l}\text { Os integrantes do } \\
\text { grupo aprendem o } \\
\text { que é cooperação. E } \\
\text { redescobrem o } \\
\text { prazer da prática }\end{array}$ & $\begin{array}{l}\text { Aumento social } \\
\text { entre os } \\
\text { participantes }\end{array}$ \\
\hline
\end{tabular}

Neste formato, torna-se mais fácil a visão das diferenças e semelhanças entre as definições dos autores e instituições referentes à orientação, atividades, praticantes e benefícios da Ginástica Geral. Pode-se perceber que todas as definições apresentam a mesma idéia de ginástica para todos (inclusiva e participativa), porém a orientação da FIG, tendo como base o Lazer, difere da orientação do GGU, que tem como principal proposta a capacitação e formação humana.

No final de 2006, a FIG publica, num primeiro momento via internet, um comunicado que marca a história da Ginástica Geral: a mudança de seu nome para Ginástica para Todos (Gymnastics for All). Esta decisão foi tomada pelo Comitê de GG da FIG, a partir de uma assembleia realizada com 90 países membros, para entrar em vigor em janeiro de 2007. 
A mudança sinaliza claramente tanto para a comunidade ginástica como o público em geral o importante papel que a Ginástica Geral representa como a base para todas as atividades da FIG. Além disso, o novo nome proporciona um entendimento imediato de que a modalidade oferece uma ampla gama de atividades e é de fato para todas idades, habilidades, gêneros e culturas.

Atividades de Ginástica podem ser identificadas desde os primórdios dos tempos e estas são atividades conhecidas hoje como Ginástica Geral - especificamente desenvolvida para melhorar a saúde e fitness das pessoas ou praticada como pura forma de divertimento e simples relaxamento. Com isso, a Ginástica oferece enormes benefícios para a saúde, sociais e educacionais, e a mudança de nome sinaliza para o mundo o importante papel, e o compromisso, que a FIG tem em contribuir para a saúde, fitness e amizade globais ${ }^{1}$.

No Brasil, a ginástica geral vem se desenvolvendo a partir de diferentes ações, e este processo se intensificou aproximadamente nos últimos 15 anos, principalmente devido a partir de alguns movimentos como:

- Encontro de Ginástica Geral realizado na Unicamp no ano de 1996;

- Fórum Brasileiro de Ginástica Geral, em parceria com o SESC em 1999, também na Unicamp. Em 2001, 2003, 2005, 2007, 2010 e 2012 este Fórum ganhou espaço internacional sob o nome de Fórum Internacional de Ginástica Geral;

- Eventos científicos organizados pela Federação Paulista de Ginástica (Encontro de Ginástica Geral, 2002) e pela Confederação Brasileira de Ginástica (Fórum Internacional de Ginástica Geral, 2003);

- Festivais de ginástica geral, organizados por diferentes órgãos (secretarias municipais e estaduais, federações e confederações, faculdades, clubes etc) ou eventos acadêmico-científicos, durante todo o ano, para os mais diferentes perfis de público;

- Itinerância do Grupo Ginástico Unicamp em diferentes eventos, escolas (públicas e privadas), clubes, associações (como o SESC), universidades

\footnotetext{
${ }^{1}$ Versão original em inglês, consultar a homepage da FIG: http://www.fig-gymnastics.com. Acesso em: 25 nov. 2006. Tradução de Luciano Truzzi.

Conexões: revista da Faculdade de Educação Física da UNICAMP, Campinas, v. 10, n. Especial, p. 10-27, dez. 2012.15 ISSN: 1983-9030
} 
(públicas e privadas) etc, em diferentes cidades do estado de São Paulo e em outras regiões do país (análise da trajetória do grupo em www.ggu.com.br );

- O desenvolvimento de grupos universitários de Ginástica Geral em diferentes regiões do país, e em universidades de grande influência em suas respectivas regiões (análise dos grupos universitários que se apresentam nos Fóruns Internacionais de Ginástica);

- dentre outros.

Com base nestes dados (obtidos por meio de uma análise dos títulos dos trabalhos de todos os Anais da área da Ginástica Geral, contidos na GÍMNICA - Biblioteca Virtual de Ginástica), e com base em outros da trajetória histórica da GG no Brasil, Toledo ${ }^{8}$ destaca o papel fundamental que os centros universitários (em especial a FEF/UNICAMP) tiveram não só para a produção de conhecimento nesta área específica, mas como para sua divulgação, por meio de diferentes ações: disciplinas da graduação e pós-graduação, projetos de extensão, pesquisas, intercâmbios nacionais e internacionais, encontros, fóruns, simpósios, festivais etc. E nestes centros universitários, os grupos de apresentação possuem papel vital para a divulgação da GG, uma vez que levam os conhecimentos sobre a prática numa linguagem não verbal ou escrita, veiculando-a de maneira mais accessível à comunidade (do que pelos trabalhos acadêmicos) ${ }^{2}$.

A combinação de pressupostos teóricos e da prática docente (em grupos de apresentação e nas aulas de graduação), ambos em ascensão na década de 90, faz surgir uma das propostas conceituais mais difundidas de GG na atualidade no Brasil:

\begin{abstract}
uma manifestação da cultura corporal, que reúne as diferentes interpretações da Ginástica (Natural, Construída, Artística, Rítmica Desportiva, Aeróbica, etc.) integrando-as com outras formas de expressão corporal (Dança, Folclore, Jogos Teatro, Mímica, etc.), de forma livre e criativa, de acordo com as características do grupo social e contribuindo para o aumento social entre os participantes. ${ }^{9: 292}$
\end{abstract}

A proposta pedagógica para o ensino da ginástica geral desenvolvida por Souza ${ }^{7}$ tem como princípios básicos: a Formação Humana e Capacitação. ${ }^{10}$ Nesta visão o professor tem papel relevante na vivência de valores significativos para o ser humano como a

\footnotetext{
${ }^{2}$ O GGU vem sendo um dos principais veículos de difusão e divulgação das pesquisas na área da Ginástica Geral da Unicamp. Suas propostas são divulgadas por meio de palestras, cursos e apresentações em diversos eventos nacionais e internacionais, em 20 anos de história. A trajetória deste grupo, assim como demais informações sobre o mesmo, podem ser consultadas no site www.ggu.com.br.

Conexões: revista da Faculdade de Educação Física da UNICAMP, Campinas, v. 10, n. Especial, p. 10-27, dez. 2012.16 ISSN: 1983-9030
} 
criatividade, o respeito às normas e leis estabelecidas pelo grupo e da sociedade como um todo, o espírito crítico, a honradez, a afetividade, a liberdade, a disponibilidade de estar a serviço do grupo, entre outros.

Concomitante a esta trajetória ascendente de produção de conhecimento e prática da GG, é perceptível que muitos profissionais e leigos na área da Ginástica, e da Educação Física, ainda desconhecem esta manifestação. E foi esta percepção que motivou um estudo de caso.

\section{O ESTUDO DE CASO}

Considerando-se que o Grupo Ginástico Unicamp e o Grupo de Pesquisa em Ginástica, ambos da FEF/UNICAMP, destacam-se pela produção e divulgação na área da ginástica geral, a pesquisa buscou identificar os conhecimentos dos alunos desta Universidade acerca da Ginástica Geral, visando compreender problemáticas e oferecer propostas para sua melhor e/ou maior divulgação.

Para atender a este objetivo, utilizou-se a técnica de documentação direta, que é constituída pela observação direta intensiva, apresentando a técnica de observação. ${ }^{11}$ Para a obtenção desta documentação, se utilizou os meios de comunicação disponíveis e mais utilizados na Unicamp como: o jornal da Unicamp, o Portal da Unicamp on line e o Sistema de Bibliotecas da Unicamp - SBU. Cada instituto, ou faculdade, ainda tem seu próprio website e suas formas de comunicação interna (jornal, boletim, quadros de avisos, dentre outros).

Utilizou-se também outras fontes de divulgação da Ginástica (abrangendo todas suas modalidades) em âmbito nacional, como os websites da CBG (www.cbginastica.com.br) e do Ginásticas (www.ginasticas.com). Porém, não há conhecimento de jornais ou de 
revistas nessa área no país, o que torna restrito o acesso de uma grande parcela da população a informações pertinentes à ginástica. Especificamente na área da Ginástica Geral, há o website do GGU e a página on line do Grupo de Pesquisa em Ginástica da FEF/UNICAMP (GPG).

Optou-se também por uma pesquisa de campo, com as seguintes características e dados, descritos abaixo.

\section{Tipo de pesquisa}

Foram utilizados os conceitos segundo Marconi e Lakatos. ${ }^{11}$ Usou-se de técnica para coleta de dados: a documentação direta, que se especifica em observação direta extensiva contendo a técnica de questionário.

\section{Universo/Amostra}

O campus da Unicamp em Campinas é composto por 10 institutos e 9 faculdades, constituindo um universo de 16.049 estudantes regulares de graduação (número disponível na EPLAN para o ano de 2006, planilha do sistema interno da Diretoria Acadêmica - DAC da Unicamp). A amostragem foi composta por 100 questionários de institutos e 45 das faculdades, totalizando 145 alunos questionados.

\section{Instrumento}

O instrumento utilizado foi o questionário de acordo com os conceitos de Marconi e Lakatos $(2001)^{3}$. Tem como objetivo principal diagnosticar o conhecimento sobre a Ginástica Geral entre os alunos de graduação da Unicamp. E foi constituído de 10 questões sendo essas 6 fechadas e 4 abertas ${ }^{4}$.

\section{Apresentação e Análise dos Resultados}

Nota-se, que mesmo a Ginástica Geral sendo uma modalidade ginástica não competitiva e voltada para todos, e tendo como seus maiores divulgadores grupos da própria UNICAMP, um elevado número de alunos da universidade desconheciam essa prática e o GGU. Isto foi comprovado nas respostas obtidas durante a pesquisa de campo.

\footnotetext{
${ }^{3}$ Estes autores preconizam que o instrumento deve ser "constituído por uma série de perguntas que devem ser respondidas por escrito e sem a presença do pesquisador". (MARCONI; LAKATOS, 2001, p. 107).

${ }^{4} \mathrm{O}$ instrumento da pesquisa encontra-se na forma de APÊNDICE no final do trabalho original.

Conexões: revista da Faculdade de Educação Física da UNICAMP, Campinas, v. 10, n. Especial, p. 10-27, dez. 2012.18 ISSN: 1983-9030
} 

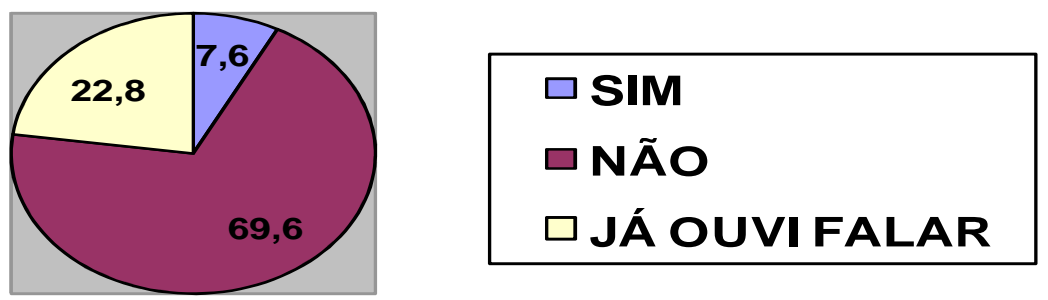

Esse número é baixo se considerarmos o conhecimento da Ginástica Geral em países Europeus, entretanto, se avaliarmos a realidade brasileira, talvez esse número não seja tão pequeno.

Nas duas questões seguintes pediu-se uma definição de Ginástica Geral tanto para os alunos que conheciam como para os que desconheciam a modalidade. As respostas foram variadas, umas mais completas e outras menos, por vezes confundiam as modalidades ginásticas ou mesmo a Ginástica Geral sendo uma ginástica que trabalhe o corpo como um todo.

Na questão número 2 checou-se o conhecimento dos sujeitos sobre o Grupo Ginástico Unicamp.

QUESTÃO 2 - Você conhece o Grupo Ginástico da Unicamp (GGU)?
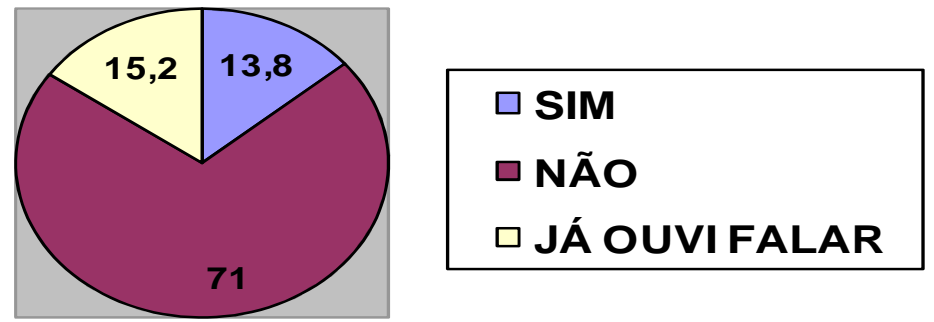

Sobre a divulgação da Ginástica Geral e do GGU nos meios de comunicação internos e Conexões: revista da Faculdade de Educação Física da UNICAMP, Campinas, v. 10, n. Especial, p. 10-27, dez. 2012.19 ISSN: 1983-9030 
externos à Unicamp obteve-se respostas também negativas $(92,4 \%$ nunca tiveram contato com nenhum tipo de divulgação do GGU em seus institutos e faculdades). Já as fontes ou meios, para que o conhecimento chegasse aos alunos, citados foram diversos, porém a comunicação simplesmente feita através da linguagem oral e corporal, ainda atua de maneira expressiva (conversa com colegas, apresentações de grupos e etc.).

QUESTÃO 3 - Você já teve contato com algum tipo de divulgação do GGU no seu instituto ou Faculdade?

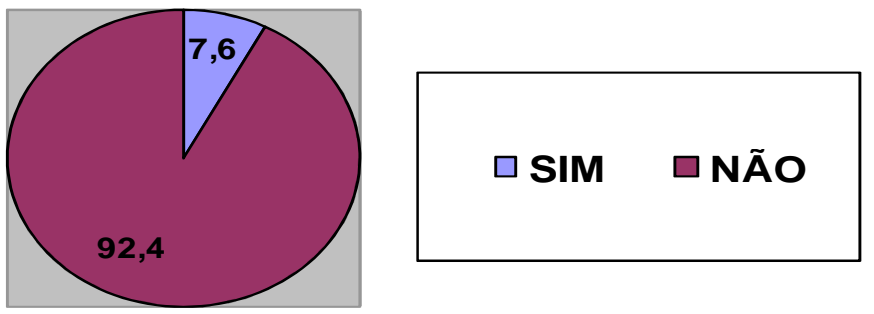

A partir dos resultados obtidos conclui-se que tanto a Ginástica Geral, como o GGU e o grupo de pesquisa, não fazem parte dos conhecimentos de uma porcentagem elevada da população estudada, e que os meios de comunicação não são efetivos para a divulgação desta manifestação entre esses alunos. Interessante paradoxo, pois embora seja um dos grupos mais conhecidos de GG, no Brasil, e com uma proposta enaltecida internacionalmente, no seu universo mais particular, é pouco conhecido. Assim como é paradoxal, de maneira mais ampla, a Unicamp destacar-se como um dos maiores polos nacionais (e internacionais) de pesquisa, e seus alunos pouco saberem o que por ela é construído. Os meios de comunicação existem, mas talvez tenham que ser melhor repensados em sua forma, conteúdo, arte, periodicidade, forma de veiculação etc. 
Estes dados deflagram algumas questões, no caso específico da GG, que parecem pontuais:

- estes grupos, de pesquisa e extensão, estão muito mais focados para uma divulgação da GG dentro da própria área da Educação Física e da Ginástica, o que parece compreensível, mas, no entanto, não totalmente adequado para uma área recente no país;

- um entendimento, por estes grupos (apresentação e pesquisa), de que os recursos próprios da universidade sejam suficientes para a divulgação da proposta, sem oferecer outros mecanismos próprios para tal divulgação.

\section{APONTAMENTOS de PROPOSTAS PARA A DivUlgaÇÃo dA GINÁSTICA GERAL NO BRASIL}

A partir desta pesquisa, foi possível apontar alguns veículos de comunicação utilizados pelos grupos de pesquisa e extensão em GG da FEF/UNICAMP, e suas deficiências, em seus respectivos espectros de abrangência. A apresentação deste estudo de caso, de maneira compacta, constitui-se num interessante material para a compreensão do fenômeno da divulgação da GG no Brasil numa perspectiva mais ampla. Este estudo, apesar de ter sido realizado com uma parte muito diminuta da população, e de ter tido um lócus específico de pesquisa, demonstra uma realidade que pode ser encontrada em outras regiões do país.

Os meios de Comunicação de Massa, tanto universitários quanto os mais utilizados na área da Ginástica, condizentemente com a realidade brasileira, geralmente não são de acesso a todos, permanentes, e realizados com boa quantidade e/ou qualidade.

No cenário brasileiro, de maneira geral, algumas questões que colaboram para a uma difusão ineficiente da GG merecem destaque:

- uma população restrita, embora em ascensão, têm acesso livre (ou em casa)

à Internet. E considerando-se que a maior parte dos conhecimentos sobre a 
prática da GG são divulgados de maneira eletrônica, isso se mostra como um fator complicador;

- a formação continuada dos professores, ainda mais na área da ginástica, em escolas e universidades, é pouco incentivada (pelo poder público e privado), ainda mais se considerando que a GG é uma área relativamente nova;

- o ensino universitário, ainda também é restrito a uma pequena parcela da população, sendo que este ainda passa por um processo de sucateamento generalizado, ou seja, por esta via poucos parecem conhecer a GG, e por consequência, os graduandos de Educação Física não se tornam agentes multiplicadores da proposta (em escolas, clubes, associações etc, como professores);

- o acesso gratuito, e de boa qualidade, à cultura, ao esporte e ao lazer, ainda são pouco oferecidos pelo poder público e privado, em praças esportivas, centros comunitários, etc. E parece que quando a ginástica é ofertada pelos programas do poder público, o foco reside nas propostas de academia ou condicionamento físico (aulas de alongamento, academia da saúde, academia popular etc) o que dificulta ainda mais a vivência e o conhecimento, pelo cidadão, da GG;

- diferentemente dos países europeus, poucas são as ações compartilhadas entre poder público e privado, entre universidades e clubes (ou associações) etc, para o desenvolvimento e oferta de programas e projetos à comunidade. Isso dificulta o desenvolvimento e aplicação de pesquisas, que podem ser ampliadas para a comunidade;

- dentre outros.

No caso específico da área da Ginástica, é possível apontar outras questões que não favorecem a divulgação da GG no país: 
- a ainda baixa oferta da Ginástica como um conteúdo ou uma manifestação da cultura corporal a ser tratada na Educação Física escolar;

- a hipervalorização dos esportes que possuem um caráter competitivo (ainda mais os que são mais tradicionais), em detrimento das práticas que possuem um caráter participativo e/ou de demonstração;

- não há revistas ou jornais sobre a Ginástica (entende-se, aqui, as modalidades regulamentadas pela FIG), deste modo, o acesso às informações desta área, e da GG por conseguinte, se restringe às pessoas que possuem computadores com internet;

- o diálogo entre o universo acadêmico e os campos de intervenção/aplicação da Ginástica precisa melhorar. Ou seja, o conhecimento produzido pelas universidades, nesta área, ainda carece de mecanismos eficazes para chegar às escolas, clubes, etc, assim como à população em geral. Assim como, os saberes produzidos nestes campos de aplicação e formação, não chegam à universidade;

- não há estudos quantitativos que mostrem se a GG é uma prática gímnica desenvolvida, nos cursos de graduação em Educação Física do país, ou seja, se está presente na formação de educadores que são potencialmente divulgadores da mesma;

- atualmente há uma parceria muito tímida entre a Confederação Brasileira de Ginástica (CBG) e demais setores da sociedade para a difusão da GG, assim como esta primeira ainda parece não possuir uma política de desenvolvimento da GG (o que parece já estar se modificando frente à eleição do novo comitê) no sentido de ofertar de maneira eficiente 
informações atualizadas em seu site, eventos (festivais), cursos de capacitação, manuais de orientação ao professor etc;

- os eventos da área da ginástica, promovidos por instituições de diferentes perfis, ainda são, em sua grande parte, divulgados de forma muito regional, embora sejam de âmbito estadual, nacional e/ou internacional;

- dentre outros.

Para colaborar com a divulgação da GG no país, os apontamentos são, justamente, as respostas para as questões levantadas anteriormente. Resumidamente parece ser necessário:

- maior utilização dos recursos de comunicação, via linguagem oral e corporal (sinalizada no estudo de campo como sendo a de mais acessibilidade) para divulgá-la;

- maior organização dos grupos de apresentação de GG, realizando parcerias com empresas privadas e prefeituras municipais, para apresentações em universidades, escolas privadas e públicas, e pelas cidades vizinhas;

- maior divulgação de eventos da área em páginas eletrônicas das universidades e faculdades. Visto que as informações do Grupo de Pesquisa em Ginástica e do GGU são apenas postadas no site da Faculdade de Educação Física e não na página oficial da Unicamp, as informações ficam restritas ao público que acessa este site;

- criação de páginas eletrônicas pelos outros grupos ginásticos existentes no Brasil, a exemplo do site do GGU, que apresenta informações sobre o grupo, de sua proposta de Ginástica Geral e links de outras instituições relacionadas; 
- maior aparição da Ginástica Geral nas páginas eletrônicas da área da Ginástica, já existentes (principalmente da CBG), assim como, maior oferta de informações sobre a mesma;

- maior investimento na GÍMNICA - Biblioteca Virtual de Ginástica (www.ginasticas.com), que lançada no IV Fórum Internacional de Ginástica Geral (2007), funciona como um centro virtual de publicações na área da Ginástica (incluindo um setor específico para a GG);

- criação de uma revista ou jornal brasileiro de ginástica, que possibilitasse a todos o contato com as informações atualizadas da área. Ou até mesmo um boletim virtual, que cumpra de algum modo esta função;

- e, por fim, a aparição da Ginástica Geral na mídia televisiva, principalmente dos grandes festivais a exemplo da Europa, lembrando que a Gymnaestrada Mundial (maior evento da área, quadrianual) apresenta um número de participantes superior ao dos Jogos Olímpicos. Ela somente foi exposta em 2011 por um canal pago, e mesmo assim parcialmente (somente o festival de abertura e encerramento), o que já se considera uma conquista. Algumas parcerias com universidades, clubes, secretarias e com a própria CBG poderiam potencializar esta divulgação de outros eventos de GG na mídia televisiva

\section{CONSIDERAÇÕES FINAIS}

Espera-se, a partir destes dados e apontamentos, contribuir para a mudança desta problemática e melhorar a difusão da Ginástica Geral no Brasil, à medida que estamos colaborando para a produção de conhecimento acerca desta temática, assim como, trazendo reflexões e apontamentos para a modificação de seu cenário. 
E finalizando este artigo, reforçamos o quão é necessário o envolvimento de diferentes setores e de diferenciados perfis de profissionais, em suas ações específicas, assim como, maior relação intersetorial para ações diversas em prol da GG (eventos, pesquisas, propostas públicas e privadas etc) para que alcancemos uma maior divulgação e legitimidade da Ginástica Geral (ou GPT).

\section{REFERÊNCIAS}

${ }^{1}$ CRUZ, B. C. A.; SOUZA, E. P. M. O conhecimento sobre a ginástica geral na Unicamp. In: SIMPÓSIO DE GINÁSTICA: FORMAÇÃO E INTERVENÇÃO EM FOCO, Maringá, 2008. Anais... Maringá: UEM/CCS/DEF, 2008. p.107-109.

${ }^{3}$ SANTOS, J. C. E. Uma visão objetiva da Ginástica Geral na atualidade brasileira. In: FORUM BRASILEIRO DE GINÁSTICA GERAL. 1., Campinas, 1999. Anais... Campinas: UNICAMP: SESC, 2000. p. 24-28.

${ }^{4}$ SOUZA, E. P. M.; PEREZ GALLARDO, J. S. Ginástica geral: duas visões de um fenômeno - uma análise histórica. In: ENCONTRO DE GINÁSTICA GERAL, 1., 1996, Campinas, SP. Coletânea: textos e síntese do I e II Encontro de Ginástica Geral. Campinas: Gráfica Central da Unicamp, 1997. p. 33-36.

${ }^{5}$ TOLEDO, E.; SCHIAVON, L. M. Ginástica geral: identidade e diversidade. In: PAOLIELLO, E. (Org.). Ginástica geral: desafios e reflexões. Barueri: Phorte, 2010. www.fig-gymnastics.com>. Acesso em: 26 de nov. 2006.

${ }^{6}$ SANTOS, J. C. E.; SANTOS, N. G. M. Ginástica geral: elaboração de coreografias e organização de festivais. Jundiaí: Fontoura, 2001.

${ }^{7}$ AYOUB. E. Ginástica geral e educação física escola. 2. ed. Campinas: Ed. da Unicamp, 2008. 
${ }^{8}$ TOLEDO, E. O papel da universidade no desenvolvimento da Ginástica Geral no Brasil. In: FÓRUM INTERNACIONAL DE GINÁSTICA GERAL, 3., Campinas, 2005. Anais... Campinas: SESC: UNICAMP/FEF, 2005. p.195-198.

${ }^{9}$ PÉREZ-GAllardo, J. S.; SOUZA, E. P. M. La experiência del Grupo Ginástico Unicamp en Dinamarca. In: CONGRESSO LATINO AMERICANO - ICHPER, 3., Foz do Iguaçu, 1995. Anais... Foz do Iguaçu, 1995. p. 292-298.

${ }^{10}$ MATURANA, H.; REZEPKA, S. N. Formación humana y capacitación. Santiago: Dlmen, 1995.

${ }^{11}$ MARCONI, M. A.; LAKATOS, E. M. Metodologia do trabalho científico: procedimentos básicos, pesquisa bibliográfica, projeto e relatório, publicações e trabalhos científicos. 6. ed. São Paulo: Atlas, 2001.

Sites:

www.ggu.com.br>. Acesso em: 28 de nov. 2006.

www.ginasticas.com/conteudo/cont_biblioteca.html

Conexões: revista da Faculdade de Educação Física da UNICAMP, Campinas, v. 10, n. Especial, p. 10-27, dez. 2012.27 ISSN: 1983-9030 